\title{
EXPRESSÃO DE ISOENZIMAS APÓS A PRÉ-HIDRATAÇÃO DE SEMENTES DE ERVILHA ${ }^{1}$
}

\author{
CAROLINE JÁCOME COSTA², FRANCISCO AMARAL VILLELA ${ }^{3}$, MIRELA ROSSETTO BERTONCELLO ${ }^{4}$, \\ MARIA ÂNGELA ANDRÉ TILLMANN5, NILSON LEMOS DE MENEZES ${ }^{6}$
}

\begin{abstract}
RESUMO - O presente trabalho teve o objetivo de estudar alterações no padrão de expressão dos sistemas isoenzimáticos malato desidrogenase e fosfatase ácida de sementes de ervilha submetidas a diferentes métodos de pré-hidratação para condução do teste de condutividade elétrica. Foram utilizados lotes de sementes de ervilha das cultivares Axé e Maria, caracterizados quanto ao teor de água, geminação, primeira contagem de germinação, envelhecimento acelerado, condutividade elétrica e emergência de plântulas em campo. As sementes de cada lote foram pré-hidratadas empregando atmosfera saturada e substrato umedecido, até atingirem teores de água de 10, 12 e 14\%. Os resultados mostraram que a pré-hidratação de sementes de ervilha utilizando atmosfera saturada ou substrato umedecido até teores de água de $10 \%$ a 14\% não foi suficiente para provocar alterações acentuadas na atividade da malato desidrogenase, após seis horas de imersão das sementes em água. Os resultados mostram diferenças na expressão diferencial do sistema isoenzimático fosfatase ácida, o qual dependeu da cultivar, do método empregado para a pré-hidratação das sementes e do teor de água final. Esses resultados indicam diferenças na capacidade de reestruturação do sistema de membranas entre cultivares de tegumento liso e rugoso e sugere a necessidade de aprimoramento dos métodos de pré-hidratação de sementes a serem submetidas ao teste de condutividade elétrica.
\end{abstract}

Termos para indexação: Pisum sativum, integridade de membranas, malato desidrogenase, fosfatase ácida.

\section{ISOENZYMATIC EXPRESSION AFTER PEA SEED PRE-HYDRATION}

\begin{abstract}
This work aimed to study chances in the isoenzymatic expression of malate dehydrogenase and acid phosphatase of pea seeds submitted to different pre-hydration methods prior to electrical conductivity test. Pea seed lots from the cvs Axé and Maria were characterized for their water content, germination, first germination counting, accelerated aging, electrical conductivity and field seedling emergence. The seeds of each lot were pre-hydrated using two methods: saturated atmosphere and humidified substrate until 10, 12 and 14\% of water content. The results showed differential expression of acid phosphatase, which depended on the cultivar, on the pre-hydration method and on the final water content. These results indicated differences in seed cellular membrane
\end{abstract}

\footnotetext{
${ }^{1}$ Submetido em 31/01/2008. Aceito em 20/08/2008. Parte da tese de Doutorado do primeiro autor, apresentada ao Programa de Pós-Graduação em Ciência e Tecnologia de Sementes, Faculdade de Agronomia Eliseu Maciel/Universidade Federal de Pelotas (FAEM/UFPel).
}

${ }^{2}$ Eng $^{\mathrm{a}}$. Agrônoma, Pesquisadora da Embrapa Cerrados, BR 020, Km 18, Rodovia Brasília-Fortaleza, CEP 73310-970 Planaltina, DF. E-mail: caroline.costa@cpac.embrapa.br.

${ }^{3}$ Eng $^{\text {o. }}$ Agrícola, Dr., Professor Adjunto do Programa de Pós-Graduação em Ciência e Tecnologia de Sementes, FAEM/UFPel. Caixa Postal 354, CEP 96010-900 Pelotas, RS. E-mail: francisco.villela@ufpel.edu.br.
${ }^{4}$ Enga . Agrônoma, Mestranda do Programa de Pós-Graduação em Ciência e Tecnologia de Sementes, FAEM/UFPel. E-mail: mirossetto@yahoo.com. br.

${ }^{5}$ Eng. Agr ${ }^{\mathrm{a}}$., Dra ${ }^{\mathrm{a}}$, Professora do Programa de Pós-Graduação em Ciência e Tecnologia de Sementes, FAEM/UFPel. E-mail: matilman@ufpel.edu.br.

${ }^{6}$ Eng. Agr ${ }^{\circ}$, Dr., Professor Adjunto do Departamento de Fitotecnia da Universidade Federal de Santa Maria. Centro de Ciências Rurais, Departamento de Fitotecnia - Campus universitário - Camobi, CEP 97105900 Santa Maria, RS. E-mail: nlmenezes@smail.ufsm.br 
restructuring system between cultivars with smooth and wrinkled tegument and suggested the needs of improvement in the pre-hydration methods of pea seeds when submitted to the electrical conductivity test

Index terms: Pisum sativum, membrane integrity, malate dehydrogenase, acid phosphatase.

\section{INTRODUÇÃO}

Considerando a importância dos testes de vigor para avaliação do potencial fisiológico de sementes ao longo do processo produtivo, é crescente o esforço empreendido pela pesquisa no sentido da padronização e aperfeiçoamento dos mesmos.

No caso de sementes de ervilha, é notório o progresso obtido pela comunidade científica, especialmente no âmbito do comitê de vigor da ISTA - "International Seed Testing Association", no direcionamento e uniformização de metodologias referentes ao teste de condutividade elétrica. Entretanto, conforme as regras internacionais, para que o teste seja executado, recomenda-se que o teor de água das sementes encontre-se na faixa de 10 a $14 \%$. Sabe-se que, em muitas regiões produtoras do país, especialmente no Centro-Oeste, é comum que os lotes sejam comercializados com teores de água inferiores a $10 \%$, o que levanta dúvidas a respeito do método mais adequado para promover a hidratação das sementes, previamente à execução do teste de condutividade elétrica (Costa et al., 2005).

Durante a maturação das sementes ortodoxas, ocorre gradual perda de água pelos tecidos da semente. Esse processo envolve profundas alterações metabólicas e estruturais que condicionam tolerância à dessecação às sementes. Essa tolerância deve favorecer a funcionalidade e integridade dos tecidos, sobretudo no momento em que as sementes são reidratadas, previamente à retomada do crescimento e desenvolvimento do embrião, durante a germinação. Nesse sentido, tão ou mais importante do que desenvolver mecanismos de proteção que possam estar em contraposição às alterações às alterações decorrentes da perda de água no interior das células é desenvolver a habilidade de reparar possíveis danos que a reativação do metabolismo, desencadeada pela absorção de água nos tecidos, possa causar (Kermode, 1997).

Desse modo, a etapa de embebição é crítica para o sucesso do estabelecimento das plântulas no campo, dada a possibilidade de ocorrência de danos celulares em resposta à absorção desordenada de água, caso as sementes não disponham de mecanismos adequados de reparo e proteção ao seu sistema de membranas celulares, o que caracteriza o dano por embebição (Bewley, 1997; De Castro e Hilhorst, 2004; Marcos Filho, 2005). Os danos por embebição são atenuados quando a hidratação inicial das sementes ocorre com vapor de água, sob alta umidade relativa, ou quando a taxa inicial do influxo de água é reduzida por meio do revestimento das sementes (De Castro e Hilhorst, 2004).

Contudo, é provável que sementes de potencial fisiológico inferior apresentem deficiências no processo de reparo e/ou proteção ao sistema de membranas durante a fase inicial de embebição, o que poderia prejudicar todas as fases subseqüentes do processo de germinação.

A possibilidade de utilização de marcadores isoenzimáticos como ferramenta na determinação de alterações bioquímicas decorrentes do processo deteriorativo das sementes já foi ressaltada por vários autores (Shatters Jr. et al. 1994; Brandão Jr. et al., 1999; Santos et al., 2004; 2005). As enzimas relacionadas à qualidade fisiológica das sementes mais pesquisadas são aquelas que atuam no processo respiratório, como a malato desidrogenase, aquelas envolvidas no metabolismo de ligação nitrogênio-carbono, como a glutamato desidrogenase, enzimas que possuem funções específicas no metabolismo dos lipídios, a exemplo das esterases, ou, ainda, enzimas removedoras de peróxidos, como as catalases, peróxido dismutase e enzimas relacionadas à desestruturação do sistema de membranas, como a esterase e fosfatase ácida e alcalina (Carvalho et al., 2000). A malato desidrogenase é uma enzima ativada principalmente durante o processo de respiração celular, regenerando uma molécula de oxalacetato a partir da oxidação de uma molécula de malato, mantendo ativo o fluxo oxidativo durante o ciclo do ácido cítrico (ciclo de Krebs), característico de uma das etapas do processo respiratório. Durante a germinação de sementes, essa enzima também atua no processo de gliconeogênese, responsável pela geração de sacarose a partir de triacilgliceróis presentes no interior dos oleossomos, nos tecidos de reserva da semente. A fosfatase ácida participa em reações de hidrólise de ésteres, podendo atuar sobre fosfolipídios de membrana, provocando a peroxidação destes (Spinola et al., 2000).

A ISTA recomenda dois métodos para pré-hidratação de sementes que apresentem teores de água inferiores ao recomendado para a execução do teste de condutividade 
elétrica: pré-hidratação em substrato umedecido e préhidratação em atmosfera saturada. Todavia, estudos preliminares mostram haver diferenças não apenas entre a velocidade de absorção de água pelas sementes, como também diferenças na classificação dos lotes, dependendo do procedimento adotado para a pré-hidratação das sementes (Castro et al., 2005; Costa et al., 2005; Rodrigues et al., 2006).

Dessa forma, objetivou-se com o presente trabalho estudar alterações no padrão de expressão dos sistemas isoenzimáticos malato desidrogenase e fosfatase ácida de sementes de ervilha submetidas a diferentes métodos de préhidratação para condução do teste de condutividade elétrica.

\section{MATERIAL E MÉTODOS}

Os experimentos foram conduzidos na Faculdade de Agronomia "Eliseu Maciel", da Universidade Federal de Pelotas, nos laboratórios de Análise de Sementes e de Biosementes, no período de agosto de 2005 a agosto de 2006.

Foram utilizados cinco lotes de sementes de ervilha da cultivar Axé, com sementes de tegumento rugoso e quatro lotes de sementes da cultivar Maria, com sementes de tegumento liso. As sementes foram cedidas pela Embrapa Hortaliças. Os lotes foram caracterizados quanto ao teor de água, germinação, primeira contagem de germinação e vigor pelos testes de envelhecimento acelerado, condutividade elétrica e emergência das plântulas em campo.

A germinação e o teor de água dos lotes foram determinados conforme as recomendações das Regras para Análise de Sementes (Brasil, 1992). O teste de germinação foi conduzido em rolos de papel, empregando quatro amostras de 50 sementes, temperatura de $20^{\circ} \mathrm{C}$ e avaliações aos cinco e sete dias. A primeira contagem de germinação consistiu na avaliação da percentagem de plântulas normais obtidas no quinto dia após o inicio do teste de germinação. O teor de água foi determinado em duas subamostras, empregando o método da estufa a $105 \pm 3^{\circ} \mathrm{C}$, por 24 horas.

$\mathrm{Na}$ condução do teste de envelhecimento acelerado, seguiram-se as recomendações de Marcos Filho (1999), sendo as sementes distribuídas sobre telas de alumínio, fixadas no interior de caixas plásticas (tipo gerbox) contendo $40 \mathrm{~mL}$ de água destilada. As caixas foram fechadas e mantidas em câmara regulada a $41^{\circ} \mathrm{C}$ por 72 horas. Após esse período, as sementes foram colocadas para germinar conforme metodologia descrita anteriormente, computandose a percentagem de plântulas normais obtidas no quinto dia após o inicio do teste.

No teste de condutividade elétrica, quatro subamostras de 50 sementes de cada lote foram pesadas, colocadas em copos plásticos de volume $500 \mathrm{~mL}$, imersas em $250 \mathrm{~mL}$ de água deionizada e mantidas a $20^{\circ} \mathrm{C}$ durante 24 horas, conforme recomendações da ISTA (2004), sem, no entanto, ajustar o teor de água das sementes para a faixa de 10-14\%. Após esse período, determinou-se a condutividade elétrica da solução, utilizando um condutivímetro. Os resultados foram expressos em $\mu \mathrm{S} . \mathrm{cm}^{-1} \cdot \mathrm{g}^{-1} \mathrm{de}$ sementes.

Para a emergência de plântulas em campo, quatro subamostras de 100 sementes de cada lote foram semeadas em sulcos de quatro metros de comprimento e cinco centímetros de profundidade, sendo cobertas com uma fina camada de solo. A avaliação foi realizada aos 10 dias após a semeadura, computando-se o número de plântulas emergidas.

Amostras de sementes de cada lote foram submetidas a dois métodos de hidratação, até atingirem três teores de água $(10,12$ e 14\%), monitorados pelo ganho de massa, resultando 30 tratamentos para a cultivar Axé (5 lotes x 2 métodos de hidratação x 3 teores de água) e 24 tratamentos para a cultivar Maria (4 lotes x 2 métodos de hidratação x 3 teores de água). Os métodos de hidratação estão relacionados a seguir.

- Hidratação em substrato umedecido - as sementes foram mantidas entre quatro folhas de papel de germinação umedecidas com quantidade de água destilada equivalente a 2,5 vezes a sua massa, as quais foram enroladas e mantidas a $20^{\circ} \mathrm{C}$, até que as sementes atingissem os teores de água desejados.

- Hidratação em atmosfera saturada - as sementes foram colocadas sobre telas de alumínio, fixadas no interior de caixas plásticas (tipo gerbox), contendo 40 $\mathrm{mL}$ de água destilada no fundo, mantidas em câmara a $20^{\circ} \mathrm{C}$, até atingirem os teores de água desejados.

- O teor de água das sementes foi monitorado por meio da fórmula Pi (100-Ui) $=\operatorname{Pf}(100-U f)$, onde:

- Pi e Pf correspondem aos pesos inicial e final das amostras, respectivamente;

- Ui e Uf correspondem à umidade inicial e final das amostras, respectivamente.

Após a hidratação das sementes, foram retiradas amostras destinadas à caracterização do padrão de expressão dos sistemas isoenzimáticos malato desidrogenase (MDH) e fosfatase ácida (ACP).

Para a caracterização do padrão de expressão isoenzimático, quatro amostras de 25 sementes de cada tratamento foram imersas em $125 \mathrm{~mL}$ de água deionizada, a $20^{\circ} \mathrm{C}$, por seis horas, conforme Duke e Kakefuda (1981). 
Posteriormente, os eixos embrionários de cada uma das 25 sementes foram removidos, macerados em cadinho de porcelana sobre cubos de gelo e imersos na solução extratora ( 9 partes de tris-citrato $0,2 \mathrm{M}, \mathrm{pH} 8,3$ e 1 parte de borato de lítio $0,2 \mathrm{M}, \mathrm{pH} 8,3+0,15 \%$ de 2 -mercaptoetanol), na proporção 1:3 $\left(\mathrm{p} . \mathrm{v}^{-1}\right)$, permanecendo 18 horas em refrigerador, conforme o protocolo de extração empregado por Malone et al. (2006; 2007). As amostras foram posteriormente centrifugadas por cinco minutos e $25 \mu \mathrm{L}$ do sobrenadante foram aplicados em gel de poliacrilamida $6 \%$. Foram realizadas quatro réplicas, para cada uma das amostras. A eletroforese foi realizada em gel de poliacrilamida vertical, no sistema tampão contínuo, conforme descrito por Scandálios (1969), com diferença de potencial de $10 \mathrm{~V} \mathrm{~cm}^{-1}$, em câmara fria, a $4^{\circ} \mathrm{C}$, por período suficiente para que a linha de frente formada pelo azul de bromofenol atingisse a parte inferior do gel. Foram empregados os sistemas de revelação citados por Alfenas (1998), para o complexo malato desidrogenase, e o sistema proposto por Scandálios (1969) para a fosfatase ácida. Os resultados foram interpretados baseando-se na análise visual dos géis de eletroforese, levando em consideração a presença/ ausência e a intensidade das bandas formadas.

Para a caracterização dos lotes, os dados de germinação, primeira contagem de germinação, emergência de plântulas em campo, envelhecimento acelerado, condutividade elétrica e lixiviação de cálcio, potássio e magnésio foram submetidos à análise de variância, utilizando-se o delineamento inteiramente casualizado, com quatro tratamentos (lotes) para a cultivar Maria e cinco tratamentos para a cultivar Axé. As médias foram comparadas pelo teste de Tukey a 5\% de probabilidade.

Os dados de germinação, primeira contagem de germinação, emergência de plântulas em campo e envelhecimento acelerado foram transformados em arcsen $(\% / 100)^{1 / 2}$.

\section{RESULTADOS E DISCUSSÃO}

\section{Caracterização dos lotes}

$\mathrm{Na}$ Tabela 1, são apresentados os resultados de teor de água, germinação, primeira contagem de germinação, emergência de plântulas em campo, envelhecimento acelerado e condutividade elétrica, utilizados para caracterizar o potencial fisiológico dos lotes de sementes de ervilha avaliados no presente trabalho. Conforme observado, embora os lotes apresentassem diferenças quanto ao potencial fisiológico, seus teores de água foram similares, variando de $8,2 \%$ a $8,7 \%$, na cultivar Axé, e de $8,4 \%$ a $8,7 \%$ na cultivar Maria. Da mesma forma, a germinação dos lotes foi semelhante, variando de $94 \%$ a $96 \%$, na cultivar Maria e de $87 \%$ a $96 \%$, na cultivar Axé, sendo similares os lotes A, B, C e $\mathrm{D}$ e o lote $\mathrm{E}$, inferior ao lote $\mathrm{D}$, para a última cultivar.

TABELA 1. Médias do teor de água (TA), germinação (G), primeira contagem do teste de germinação (PC), emergência de plântulas em campo (EC), envelhecimento acelerado (EA) e condutividade elétrica (CE) de diferentes lotes de sementes de ervilha de duas cultivares. Pelotas/RS, 2006.

\begin{tabular}{cccccccc}
\hline Cultivar & Lotes & TA $(\%)$ & G $(\%)$ & PC (\%) & EC (\%) & EA (\%) & CE $\left(\mu \mathrm{S} \cdot \mathrm{cm}^{-1} \cdot \mathrm{g}^{-1}\right)$ \\
\hline \multirow{5}{*}{ Axé } & $\mathrm{A}$ & 8,3 & $95 \mathrm{ab}$ & $88 \mathrm{a}$ & $54 \mathrm{~d}$ & $64 \mathrm{c}$ & $28,51 \mathrm{c}$ \\
& $\mathrm{B}$ & 8,5 & $94 \mathrm{ab}$ & $86 \mathrm{a}$ & $74 \mathrm{~b}$ & $83 \mathrm{~b}$ & $16,12 \mathrm{a}$ \\
& $\mathrm{C}$ & 8,7 & $89 \mathrm{ab}$ & $80 \mathrm{a}$ & $66 \mathrm{c}$ & $74 \mathrm{bc}$ & $20,78 \mathrm{~b}$ \\
& $\mathrm{D}$ & 8,4 & $96 \mathrm{a}$ & $86 \mathrm{a}$ & $86 \mathrm{a}$ & $94 \mathrm{a}$ & $15,64 \mathrm{a}$ \\
& $\mathrm{E}$ & 8,2 & $87 \mathrm{~b}$ & $84 \mathrm{a}$ & $67 \mathrm{c}$ & $76 \mathrm{bc}$ & $19,24 \mathrm{ab}$ \\
\hline \multirow{6}{*}{ Maria } & $\mathrm{CV}(\%)$ & & 5,31 & 5,44 & 7,38 & 7,48 & 8,39 \\
& $\mathrm{~F}$ & 8,6 & $94 \mathrm{a}$ & $93 \mathrm{a}$ & $83 \mathrm{a}$ & $91 \mathrm{a}$ & $16,50 \mathrm{a}$ \\
& $\mathrm{G}$ & 8,7 & $94 \mathrm{a}$ & $90 \mathrm{a}$ & $77 \mathrm{~b}$ & $86 \mathrm{a}$ & $16,28 \mathrm{a}$ \\
& $\mathrm{H}$ & 8,4 & $94 \mathrm{a}$ & $90 \mathrm{a}$ & $78 \mathrm{~b}$ & $88 \mathrm{a}$ & $18,84 \mathrm{~b}$ \\
& $\mathrm{I}$ & 8,4 & $96 \mathrm{a}$ & $94 \mathrm{a}$ & $80 \mathrm{ab}$ & $91 \mathrm{a}$ & $14,72 \mathrm{a}$ \\
\hline
\end{tabular}

Médias seguidas pela mesma letra na coluna, para cada cultivar, não diferem entre si pelo teste de Tukey a 5\% de probabilidade. Dados não transformados.

Verificou-se que, dos testes empregados para avaliação do potencial fisiológico dos lotes de sementes de ervilha da cultivar Axé, os testes de envelhecimento acelerado e emergência de plântulas em campo possibilitaram classificar os lotes em níveis de vigor, separando-os em lotes de alto (lote D), médio (lotes B, C e E) e baixo (lote A) potencial 
fisiológico. Os resultados do teste de condutividade elétrica também permitiram a separação dos lotes em três níveis de vigor: alto (lotes $\mathrm{B}$ e $\mathrm{D}$ ), médio (lotes $\mathrm{C}$ e $\mathrm{E}$ ) e baixo (lote $\mathrm{A}$ ). Para a cultivar Maria, os resultados do teste de emergência de plântulas evidenciaram a superioridade do lote $\mathrm{F}$ em relação aos lotes $\mathrm{G} \mathrm{e} \mathrm{H}$, sendo o lote I considerado como de potencial fisiológico intermediário. $\mathrm{O}$ teste de condutividade elétrica, por outro lado, possibilitou apenas a separação do lote H, considerado de menor potencial fisiológico, relativamente aos demais.

\section{Padrão de expressão dos sistemas isoenzimáticos}

Para cada cultivar, apenas os perfis eletroforéticos dos lotes com resultados mais significativos foram apresentados.

Para o sistema isoenzimático malato desidrogenase, verificou-se que não ocorreram alterações na expressão desta enzima resultantes da pré-hidratação das sementes, tanto em relação aos métodos empregados, quanto aos teores de água alcançados nas duas cultivares (Figuras 1 e 2). Da mesma forma, em estudos com sementes de soja Shatters et al. (1994), observaram que a atividade da malato desidrogenase foi a menos afetada pelos tratamentos de envelhecimento acelerado das sementes. Santos et al. (2005) observaram que a atividade da malato desidrogenase permaneceu estável em sementes de feijão de maior potencial fisiológico. Em sementes de milho, a malato desidrogenase manteve seus padrões isoenzimáticos inalterados com o avanço do processo deteriorativo (Spinola et al., 2000).

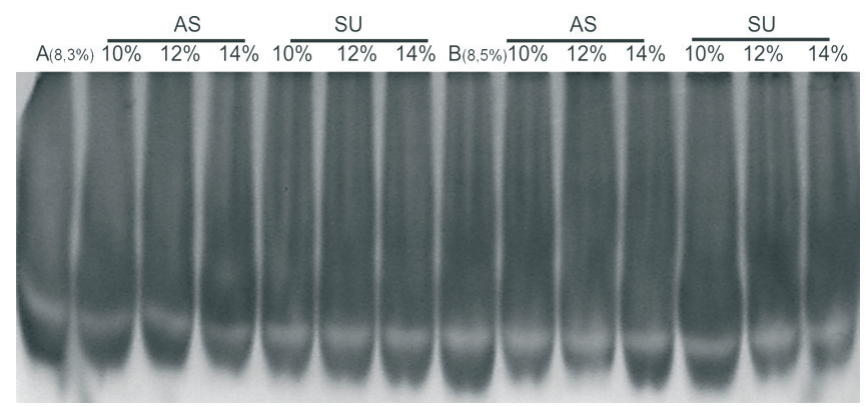

FIGURA 1. Padrão eletroforético de sementes de ervilha, cultivar Axé, lotes A e B, para o sistema enzimático malato desidrogenase, após hidratação em atmosfera saturada (AS) e substrato umedecido (SU) até teores de água de 10,12 e $14 \%$. $\mathrm{A}(8,3 \%)$ e $\mathrm{B}(8,5 \%)$ : sementes não hidratadas dos lotes $\mathrm{A}$ e $\mathrm{B}$, respectivamente. Pelotas/RS, 2006.

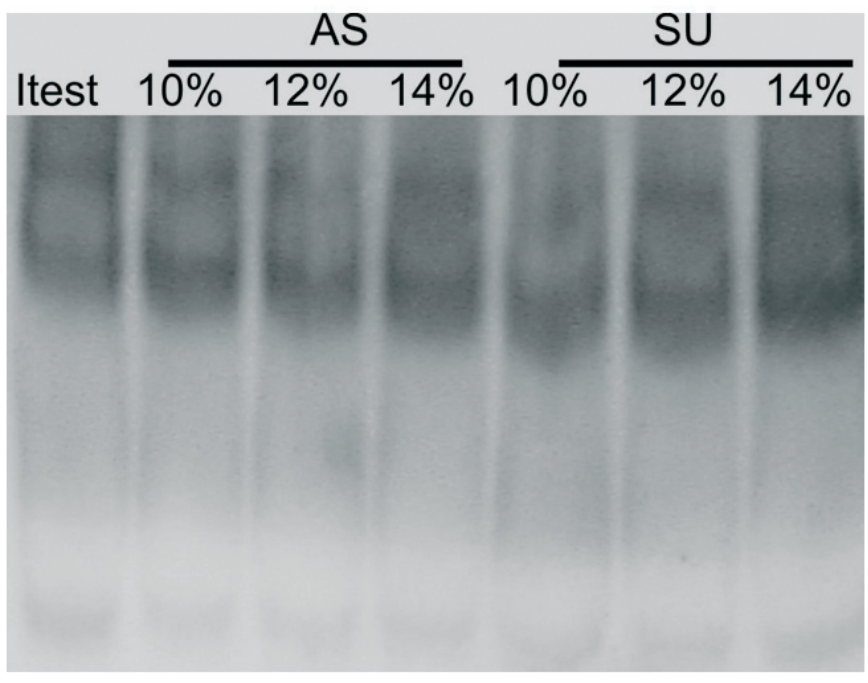

FIGURA 2. Padrão eletroforético de sementes de ervilha, cultivar Maria, lote I, para o sistema enzimático malato desidrogenase, após hidratação em atmosfera saturada (AS) e substrato umedecido (SU) até teores de água de 10, 12 e 14\%. I(test): sementes não hidratadas do lote $I$, com teor de água de 8,4\%. Pelotas/RS, 2006.

A fosfatase ácida, por sua vez, é uma enzima relacionada a processos deteriorativos em sementes, como a desestruturação do sistema de membranas celulares, provocado pela peroxidação dos fosfolipídios de membrana (Carvalho et al., 2000; Spinola et al., 2000; Santos et al., 2005). A análise visual dos géis de eletroforese obtidos no presente trabalho permitiu observar que, para a cultivar Axé, a intensidade na expressão desse sistema enzimático foi geralmente maior ao empregar o método de substrato umedecido para a pré-hidratação das sementes, conforme se observou no lote C (Figura 3). Contrariamente, em alguns lotes avaliados, o emprego de atmosfera saturada com o mesmo intuito reduziu a intensidade das bandas formadas, indicando que esse método parece ter sido benéfico, do ponto de vista da reestruturação do sistema de membranas, conforme observado no lote D (Figura 4). É possível que, para essa cultivar, o método do substrato umedecido possa ter ocasionado a entrada muito rápida de água nas sementes, desfavorecendo a reparação adequada de seu sistema interno de membranas, o que resultou maior atividade do complexo enzimático fosfatase ácida, após imersão das sementes em água. Santos et al. (2004) registraram que os maiores valores de condutividade elétrica relacionaramse com maior atividade da fosfatase ácida em um lote de sementes de feijão submetidas ao envelhecimento artificial. 
Os autores sugerem que o aumento na atividade da fosfatase ácida possa ter provocado a peroxidação dos fosfolipídios de membrana, levando ao aumento na permeabilidade celular, $\mathrm{e}$, conseqüentemente, aos maiores valores de condutividade elétrica observados.

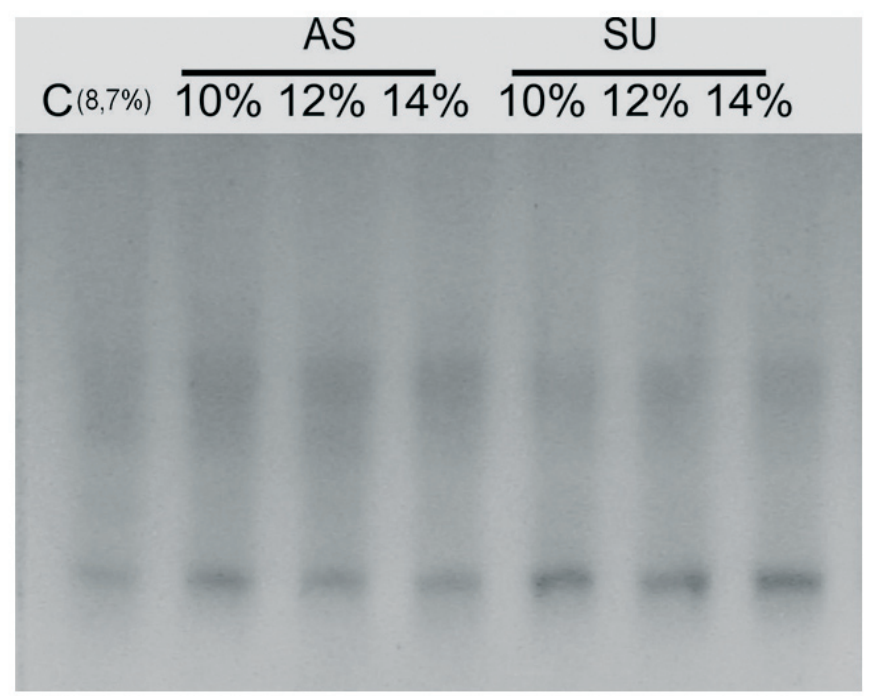

FIGURA 3. Padrão eletroforético de sementes de ervilha, cultivar Axé, lotes $\mathbf{C}$, para o sistema enzimático fosfatase ácida, após hidratação em atmosfera saturada (AS) e substrato umedecido (SU) até teores de água de 10, 12 e $14 \%$. $C(8,7 \%)$ : sementes não hidratadas do lote C. Pelotas/RS, 2006.

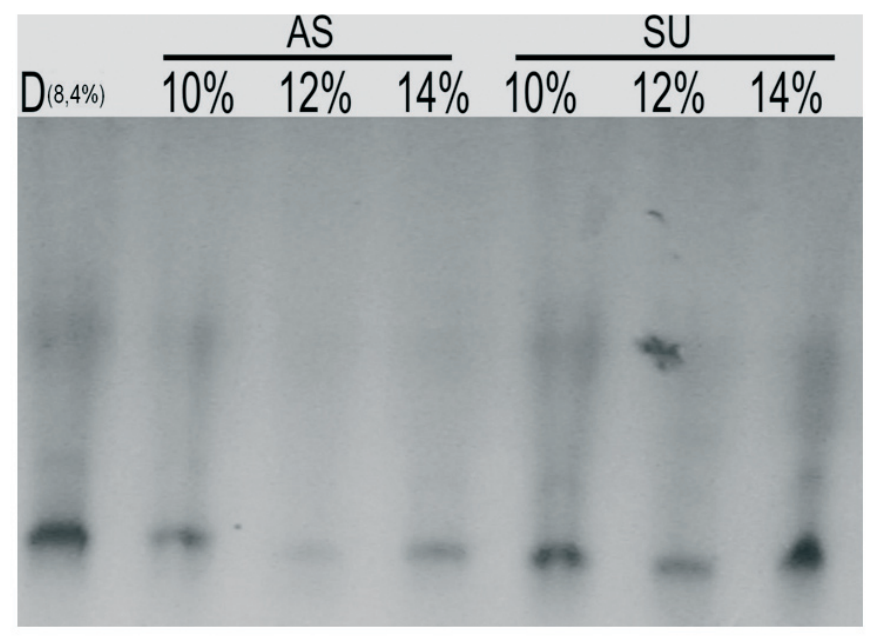

FIGURA 4. Padrão eletroforético de sementes de ervilha, cultivar Axé, lote D, para o sistema enzimático fosfatase ácida, após hidratação em atmosfera saturada (AS) e substrato umedecido (SU) até teores de água de 10, 12 e $14 \%$. $D(8,4 \%)$ : sementes não hidratadas do lote D. Pelotas/RS, 2006.
Em relação à cultivar Maria, considerando o padrão de expressão do sistema enzimático fosfatase ácida, os resultados mais expressivos foram obtidos nos lotes $\mathrm{H}$ e I. No lote $\mathrm{H}$, o método de pré-hidratação das sementes empregando atmosfera saturada até as sementes atingirem o teor de água de $12 \%$ ocasionou menor intensidade de expressão desse sistema enzimático (Figura 4). Para o lote I, entretanto, os dois métodos mostraram-se eficientes, variando apenas os teores de água das sementes (Figura 5). Assim, foi possível obter bandas de coloração menos intensa ao pré-hidratar as sementes empregando atmosfera saturada até o teor de água de $14 \%$, ou substrato umedecido até as sementes atingirem teor de água de $12 \%$. Nesse caso, é provável que o teor de água seja fator mais relevante do ponto de vista da reconstituição da integridade das membranas celulares do que o método adotado para pré-hidratação das sementes, para a cultivar Maria.

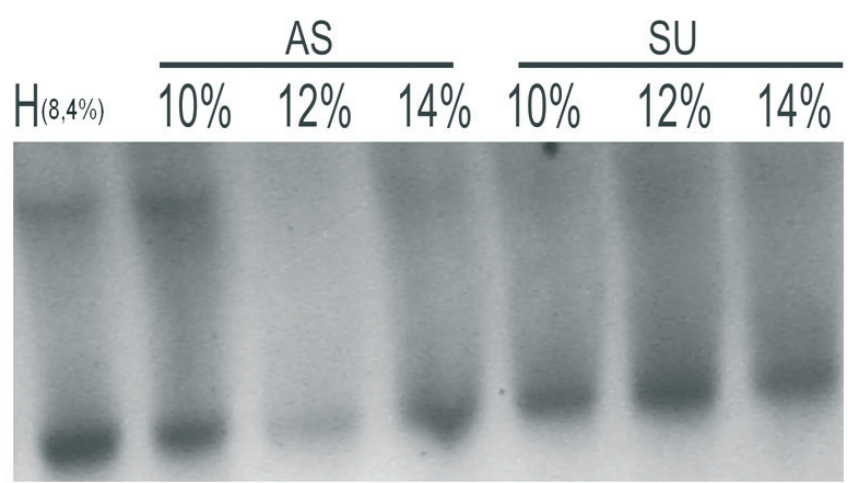

FIGURA 5. Padrão eletroforético de sementes de ervilha, cultivar Maria, lote $H$, para o sistema enzimático fosfatase ácida, após hidratação em atmosfera saturada (AS) e substrato umedecido (SU) até teores de água de 10, 12 e $14 \%$. $H(8,4 \%)$ : sementes não hidratadas do lote H. Pelotas/RS, 2006.

As diferenças de comportamento das sementes em resposta aos métodos de pré-hidratação empregados, relativamente ao padrão de expressão dos sistemas isoenzimáticos avaliados, podem refletir diferenças na composição química e características morfo-anatômicas relacionadas aos tecidos da própria semente, especialmente do tegumento, característico de cada um dos genótipos avaliados. Sabe-se que o caráter rugoso ou liso das sementes de ervilha é conferido pela mutação em um gene envolvido no padrão de síntese e ramificação do amido nas sementes, levando ao acúmulo de açúcares solúveis nas sementes de tegumento rugoso (Battacharyya et al., 1990; Smith e Denyer, 1992). Dessa forma, dependendo da cultivar, os 
métodos de pré-hidratação empregados para preparar as amostras de sementes de ervilha a serem submetidas ao teste de condutividade elétrica podem promover resultados discrepantes, alterando a avaliação do potencial fisiológico das mesmas.

Além disso, na cultivar Maria, foi possível observar o efeito do potencial fisiológico das sementes no padrão de expressão do sistema isoenzimático fosfatase ácida, em resposta aos métodos de pré-hidratação empregados. Verificou-se que, no lote de potencial fisiológico inferior (lote $\mathrm{H}$ ), o método de pré-hidratação foi determinante em relação à redução da atividade da fosfatase ácida. Nesse caso, o método de pré-hidratação empregando atmosfera saturada até as sementes atingirem o teor de água de $12 \%$ resultou em menor atividade da fosfatase ácida (Figura 6). Nos lotes de maior potencial fisiológico, a atividade da fosfatase ácida foi independente do método empregado, variando apenas em resposta ao teor de água atingido pelas sementes ao final do processo (Figura 5). Nessa circunstância, é provável que sementes de menor potencial fisiológico não disponham de mecanismos adequados de reparo e proteção ao sistema interno de membranas celulares capazes de se contrapor à rápida entrada de água nas sementes, ocasionada pelo método do substrato umedecido. Santos et al. (2005) também verificaram relação entre o potencial fisiológico inicial das sementes e a atividade da fosfatase ácida em sementes de feijão, ao longo do armazenamento, registrando os maiores aumentos na atividade da fosfatase ácida nas sementes de menor potencial fisiológico.

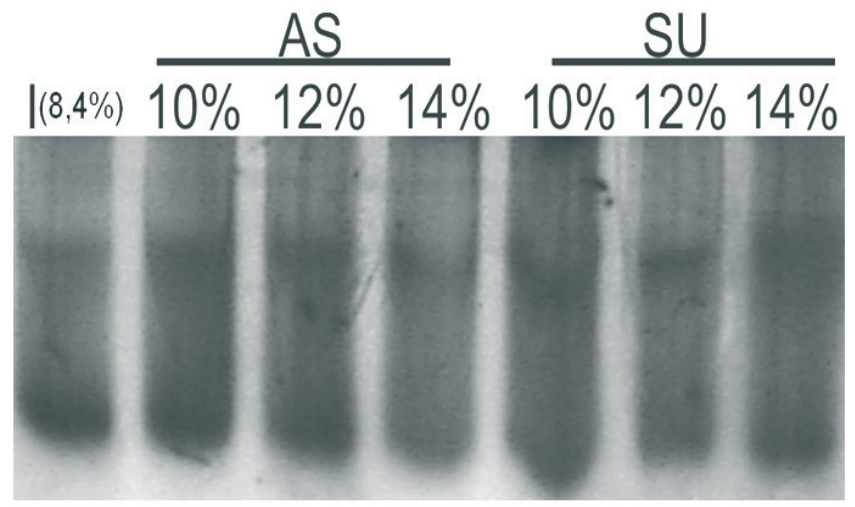

FIGURA 6. Padrão eletroforético de sementes de ervilha, cultivar Maria, lote I, para o sistema enzimático fosfatase ácida, após hidratação em atmosfera saturada (AS) e substrato umedecido (SU) até teores de água de 10, 12 e $14 \%$. I $(8,4 \%)$ : sementes não hidratadas do lote I. Pelotas/RS, 2006.
De todo modo, verificou-se que, do ponto de vista da estruturação das membranas celulares, mesmo que tenham ocorrido diferenças no comportamento das sementes das duas cultivares em relação aos métodos empregados para o ajuste do seu teor de água, em nenhum caso as alterações decorrentes da utilização de diferentes métodos de préhidratação promoveram modificações no metabolismo oxidativo das sementes. Isso pode refletir a atuação de mecanismos compensatórios que permitem a ocorrência de reparos em outros pontos e/ou etapas durante a reativação do metabolismo das sementes, como uma tentativa de dar prosseguimento normal ao processo germinativo. Nesse sentido, merecem destaque os resultados obtidos por Di Nola e Mayer (1987), que investigaram o processo de incorporação de etanolamina (um ácido graxo livre) nos fosfolipídios de membrana durante a embebição de sementes de ervilha. Os autores relataram que a embebição das sementes sob temperatura de $5^{\circ} \mathrm{C}$ provocou rápida redução no pool de etanolamina livre nas células, sugerindo sua possível incorporação na composição de fosfatidiletanolamina, um fosfolipídio de membrana. Esse padrão não foi observado ao promover a embebição das sementes a $25^{\circ} \mathrm{C}$. Sabendo que a fosfatidiletanolamina é precursora de $\mathrm{N}$-Acilfosfatidiletanolaminas, um grupo de fosfolipídios de membrana que podem atuar na estabilização das membranas celulares, muitos autores sugerem que, sob condições que favoreçam a ocorrência de danos por embebição nas células, como baixas temperaturas durante a embebição das sementes, mecanismos preventivos à ocorrência de danos podem ser acionados, reduzindo a incidência de distúrbios celulares e metabólicos que comprometam o progresso normal do processo germinativo das sementes (LaFrance et al., 1990; Shrestha et al., 2002).

Alterações que envolvam modificações na permeabilidade das membranas celulares, decorrentes da reestruturação de sua integridade e indiretamente detectadas pelo teste de condutividade elétrica podem, sendo o teste adequadamente conduzido, levar a resultados que auxiliem na distinção qualitativa entre lotes de sementes. A expressão e/ou atividade de enzimas relacionadas a processos de reparo ou degradação da integridade das membranas celulares, juntamente com o teste de condutividade elétrica, auxiliam na distinção qualitativa entre lotes de sementes.

Pelos resultados obtidos no presente trabalho, recomenda-se a utilização do padrão de expressão de sistemas isoenzimáticos específicos, como o sistema da fosfatase ácida, como uma ferramenta complementar à avaliação do potencial fisiológico de sementes, levando- 
se em consideração a relação custo-benefício desta prática. Trabalhos realizados anteriormente também já destacaram a potencialidade de alguns sistemas isoenzimáticos na indicação do estádio de deterioração de sementes de algumas espécies, como algodão (Vieira, 1996), milho (Spinola et al., 2000), feijão (Santos et al., 2004; 2005), soja e cevada (Chauhan et al., 1985), auxiliando na avaliação do potencial fisiológico das sementes. No caso de sementes florestais, Carvalho et al. (2006) observaram que os sistemas isoenzimáticos esterase e peroxidase podem ser empregados para avaliação do potencial fisiológico de sementes de copaíba durante o armazenamento, uma vez que a redução da atividade destas enzimas indica perda da capacidade germinativa das sementes.

Todavia, a ampliação do uso de marcadores moleculares para avaliação do potencial fisiológico de sementes ainda requer estudos adicionais até que seja estabelecido como uma ferramenta em programas de controle de qualidade de sementes.

\section{CONCLUSÃO}

O sistema isoenzimático fosfatase ácida apresenta alterações de expressão em função do método de préhidratação, para a cultivar de ervilha Axé, e em função do teor de água final, para a cultivar de ervilha Maria.

\section{AGRADECIMENTOS}

Ao CNPq, pelo apoio financeiro e ao Dr. Warley Marcos Nascimento, pesquisador da Embrapa Hortaliças, pelo fornecimento das sementes utilizadas nos experimentos.

\section{REFERÊNCIAS}

ALFENAS, A.C. Eletroforese de isoenzimas e proteínas afins. Viçosa: UFV, 1998. 574p.

BATTACHARYYA, M.K.; SMITH, A.M.; NOEL ELLIS, T.H.;HEDLEY, C.; MARTIN, C. The wrinkled-seed character of pea described by Mendel is caused by a transposon-like insertion in a gene encoding starch-branching enzyme. Cell, Cambridge, v.60, p. 115-122, 1990.

BEWLEY, J. D. Seed germination and dormancy. The Plant Cell, Rockville, v.9, p.1055-1066, 1997.

BRANDÃO JR.; D.S.; CARVALHO, M.L.M.; VIEIRA, M.G.G.C. Variações eletroforéticas de proteínas e isoenzimas relativas à deterioração de sementes de milho envelhecidas artificialmente. Revista Brasileira de Sementes, Brasília, v.21, n.1, p.114-121, 1999.
BRASIL. Ministério da Agricultura e da Reforma Agrária. Regras para análise de sementes. Brasília: SNDA/DNDV/ CLAV, 1992. 365p.

CARVALHO, M.L.M.; VIEIRA, M.G.G.C.; PINHO, E.R.V. Técnicas moleculares em sementes. Biotecnologia, Ciência \& Desenvolvimento, Brasília, v.3, n.17, p.44-47, 2000.

CARVALHO, D.; FERREIRA, R.A.; OLIVEIRA, L.M.; OLIVEIRA, A.F.; GEMAQUE, R.C.R. Eletroforese de proteínas e isoenzimas em sementes de Copaifera langsdorffii Desf. (Leguminosae Caesalpinoideae) envelhecidas artificialmente. Revista Árvore, Viçosa, v.30, n.1, p.19-24, 2006.

CASTRO, K.G.S.; COSTA, C.J.; VILlelA, F.A. Préhidratação e eficiência do teste de condutividade elétrica em sementes de soja de cultivares com diferença na suscetibilidade ao dano por embebição. In: CONGRESSO BRASILEIRO DE SEMENTES, 14., 2005, Foz do Iguaçu. Informativo ABRATES. Pelotas: ABRATES, 2005. v.15, n. $1 / 2 / 3$. p. 253 .

CHAUHAN, K.P.S.; GOPINATHAN, M.C.; BABU, C.R. Electrophoretic variations of proteins and enzymes in relation to seed quality. Seed Science and Technology, Zürich, v.13, n.3, p.629-641, 1985.

COSTA, C.J.; CASTRO, K.G.S.; VILlELA, F.A. Préhidratação em sementes de ervilha submetidas ao teste de condutividade elétrica. In: CONGRESSO BRASILEIRO DE SEMENTES, 14., 2005, Foz do Iguaçu. Informativo ABRATES. Pelotas: ABRATES, 2005. v.15, n.1/2/3. p.250.

DE CASTRO, R. D.; HILHORST, H. W. M. Embebição e reativação do metabolismo. In: FERREIRA, A. G.; BORGHETTI, F. (Ed.). Germinação: do básico ao aplicado. Porto Alegre: Artmed, 2004. p. 149-162.

DI NOLA, L.; MAYER, A.M. Ethanolamine incorporation into membranes of pea embryonic axes during germination. Phytochemistry, Great Britain, v.26, n.6, p.1591-1593, 1987.

DUKE, S.H.; KAKEFUDA, G. Role of the testa in preventing cellular rupture during imbibition of legume seeds. Plant Physiology, Rockville, v.67, p.449-456, 1981.

INTERNATIONAL SEED TESTING ASSOCIATION. Seed vigour testing. In: ISTA. International rules for seed testing. Bassersdorf: ISTA, 2004.

KERMODE, A.R. Approaches to elucidate the basis of desiccation-tolerance in seeds. Seed Science Research, Wallingford, v.7, n.2, p.75-95, 1997. 
LAFRANCE, D.; MARION, D.; PEZOLET, M. Study of the structure of N-Acylpalmitoylphosphstidylethanolamine in aqueous dispersion by infrared and Raman spectroscopies. Biochemistry, Washington, v.29, p. 4592-4599, 1990.

MALONE, G.; ZIMMER, P.D.; CASTRO, M.A.S.; CARVALHO, I.; MENEGHELlO, G.E.; PESKE, S.T. Identificação do estádio adequado para realização de análises isoenzimáticas na caracterização de cultivares de arroz. Revista Brasileira de Sementes, Pelotas, v.28, n.2, p.193200, 2006.

MALONE, G.; ZIMMER, P.D.; MENEGHELLO, G.E.; CASTRO, M.A.S.; PESKE, S.T. Expressão diferencial de isoenzimas durante o processo de germinação de sementes de arroz em grandes profundidades de semeadura. Revista Brasileira de Sementes, Pelotas, v.29, n.1, p.61-67, 2007.

MARCOS FILHO, J. Teste de envelhecimento acelerado. In: VIERA, R.D.; CARVALHO, N. M. (Ed.). Testes de vigor em sementes. Jaboticabal: FUNEP, 1999. p. 133-149.

MARCOS FILHO, J. Germinação. In: Fisiologia de sementes de plantas cultivadas. Piracicaba: FEALQ, 2005. p.197-252.

RODRIGUES, M.B.C.; VILLELA, F.A.; TILLMANN, M.A.A.; CARVALHO, R. Pré-hidratação em sementes de soja e eficiência do teste de condutividade elétrica. Revista Brasileira de Sementes, Pelotas, v.28, n.2, p.168-181, 2006.

SANTOS, C.M.R.; MENEZES, N.L.; VILLELA, F.A. Alterações fisiológicas e bioquímicas em sementes de feijão envelhecidas artificialmente. Revista Brasileira de Sementes, Pelotas, v.26, n.1, p.110-119, 2004.
SANTOS, C.M.R.; MENEZES, N.L.; VILLELA, F.A. Modificações fisiológicas e bioquímicas em sementes de feijão no armazenamento. Revista Brasileira de Sementes, Pelotas, v.27, n.1, p.104-114, 2005.

SCANDÁLIOS, J.G. Genetic control of multiple molecular forms of enzymes in plants: a review. Biochemical Genetics, New York, v.3, n.1, p.37-79, 1969.

SHATTERS JR., R.G;ABDEL-GHANY,A.;ELBAGOURY, O.; WEST, S.H. Soybean seed deterioration and response to priming: changes in specific enzyme activities in extracts from dry and germinating seeds. Seed Science Research, Wallingford, v.4, n.1, p.33-41, 1994.

SHRESTHA, R.; NOORDERMEER, M. A.; VAN DER STELT, M.; VELDINK, G. A.; CHAPMAN, K. D. N-Acylethanolamines are metabolized by lipoxigenase and amidohydrolase in competing pathways during cottonseed imbibition. Plant Physiology, Rockville, v.130, n. 1, p. 391401, 2002.

SMITH, A.M.; DENYER, K. Starch synthesis in developing pea embryos. New Phytologist, New York, v.122, n.1, p.2133, 1992.

SPINOLA, M.C.M.; CÍCERO, S.M.; MELO, M. Alterações bioquímicas e fisiológicas em sementes de milho causadas pelo envelhecimento acelerado. Scientia Agricola, Piracicaba, v.57, n.2, p.263-270, 2000.

VIEIRA, M.G.G.C. Utilização de marcadores moleculares no monitoramento da qualidade sanitária e nível de deterioração de sementes de algodoeiro (Gossypium hirsutum L.). 1996. 114f. Tese (Doutorado em Fitotecnia) Universidade Federal de Lavras, Lavras, 1996. 